\title{
Antoine Berman: para além do albergue do longínquo
}

\author{
Simone C. Petry e Mauricio Mendonça Cardozo*
}

Parler de traduction, c'est parler des œuvres, de la vie, du destin et de la nature des cuvres; de la manière dont elles éclairent nos vies; c'est parler de la communication, de la transmission, de la tradition; c'est parler du rapport du Propre et de l'Étranger; c'est parler de la langue maternelle, natale, et des autres langues; c'est parler de l'etreen-langues de l'homme; c'est parler de l'écriture et de l'oralité; ; cest parler du mensonge et de la vérité, de la trahison et de la fidélité; c'est parler du mimétique, du double, du leurre, de la secondarité; c'est parler de la vie du sens et de la vie de la lettre; c'est... être pris dans un enivrant tourbillon réflexif où le mot "traduction» lui-même ne cesse de se métaphoriser.

ANTOINE BERMAN ${ }^{1}$

L'œuvre d'Antoine Berman est éminemment politique. Pour qu'elle soit "reçue» véritablement, la pensée, en elle-même - comme le poème -, devrait avoir à nouveau droit de cité, être désirée, soutenue, exercée, reconnue comme éloquente et nécessaire.

ISABELLE BERMAN ${ }^{2}$

*UFSC; UFPR/CNPq

1 "Au début était le traducteur", texto inédito de Antoine Berman nesta edição da Tradução em Revista.

2 "Pour Antoine Berman, 30 ans apres", texto de Isabelle Berman para esta edição da Tradução em Revista. 
O modo de circulação e recepção do pensamento teórico-crítico é um tema amplo e complexo, ao qual o campo dos Estudos da Tradução dedicou, até o presente momento, uma atenção apenas muito discreta. Não há dúvida de que muitos são os fatores que determinam a sua disseminação. E se podemos presumir que certos aspectos, como a publicação em veículos de menor ou maior alcance, o apoio institucional (ou a falta deste) e a adesão ou resistência a tendências dominantes, entre outros, possam contribuir de modo significativo para a sua recepção, a língua em que esses trabalhos são escritos originalmente está longe de ser uma questão menor.

Vivemos uma época em que trabalhos publicados em língua inglesa alcançam, não raro, uma disseminação em escala global, e isso não se dá necessariamente pela maior contribuição ou relevância desses trabalhos para a pesquisa e o pensamento contemporâneos sobre a tradução, mas, em grande medida, por força da presença estruturante dessa língua nas redes de disseminação do conhecimento mundo afora. O mesmo não parece ocorrer, nem na mesma escala nem na mesma frequência, com trabalhos escritos originalmente e publicados predominantemente em outros idiomas que não o inglês. Sua circulação pode se dar de modo suficientemente heteróclito, a ponto de desenhar cenas de recepção muito distintas de língua para língua, país para país, e não somente em razão da presumível diferença de interesse e impacto de determinada obra em contextos linguísticos, culturais e acadêmicos diferentes, mas também em razão do recorte particular da obra que ganha maior ou menor destaque em cada uma de suas cenas de recepção, metonimizando a obra de modo particular.

Este parece ser o caso de um autor como Antoine Berman (1942-1991), como apontam as diferentes caracterizações que dele são feitas em cada língua, sintetizadas dos mais diversos modos no corpo de artigos de pesquisadores contemporâneos, mas também multiplicadas em páginas de vulgarização do conhecimento na internet. Para a Wikipedia de língua francesa, por exemplo, trata-se de um linguista, teórico da tradução e tradutor do alemão e do espanhol (para o francês); para a de língua alemã, trata-se de um crítico literário, filósofo 
e teórico da tradução; para a de língua inglesa, trata-se de um tradutor, filósofo, historiador e teórico da tradução. ${ }^{3}$

A faceta de "teórico da tradução" se repete em todas as versões, mas mesmo sendo possivelmente a mais evidente - ao menos num sentido vago e genérico do que se possa associar ao fazer de um "teórico" -, a rubrica não leva em conta, por exemplo, a resistência do próprio autor a entender a tradução a partir de uma visão categórica e dicotômica da relação entre "teoria" e "prática", tampouco tira consequências de seu modo decisivo de pensar e de viver a tradução a partir da tensão que se instaura entre "reflexão" e "experiência". É notável, também, como algumas dessas facetas só parecem se revelar em determinadas línguas: a de linguista, em francês; a de crítico literário, em alemão; e a de historiador, em inglês. E é igualmente digno de nota que algumas dessas facetas simplesmente não sejam destacadas nas versões do perfil do autor em determinadas línguas: a de tradutor, na página em alemão, ou a de filósofo, na versão em francês. Seriam essas discrepâncias meramente casuais, um simples efeito da própria dinâmica de construção desses perfis? Ou caberia considerar essas diferenças como sintomas de visões mais amplamente disseminadas do autor e de sua obra? Seja como for, já a dificuldade para avaliar o apropriado dos destaques e/ou o inapropriado das lacunas nos dá uma boa medida do quanto ainda temos a descobrir sobre Antoine Berman.

Não há dúvidas de que é preciso ir muito além dessas impressões para se poder detalhar as diferenças da recepção da obra de Antoine Berman em contextos tão amplos e heterogêneos como os de língua francesa, de língua alemã, de língua inglesa, de língua portuguesa, entre outros. Mas não é preciso ir tão longe assim para constatar que as diferenças existem e não são irrelevantes. Se em alguns desses contextos a recepção de sua obra ainda é muito discreta e episódica - como podemos arriscar dizer que é o caso de sua recepção em língua alemã, ao menos até o presente momento -, em outros contextos a recepção de sua obra é cada vez mais abrangente e produtiva, incluindo até mesmo o recente interesse por trabalhos anteriores ao seu envolvimento com a

\footnotetext{
3 Vide: https://fr.wikipedia.org/wiki/Antoine_Berman, https://de.wikipedia.org/wiki/Antoine_Berman e https://en.wikipedia.org/wiki/Antoine_Berman. Acesso em 22.05.2021.
} 
tradução - como é o caso do contexto brasileiro e de pesquisas que estudam as relações de Berman com a América do Sul. Por sua vez, também são consequentemente muito distintos o lugar desse autor e o impacto de sua obra na pesquisa e no pensamento sobre a tradução em cada um desses contextos, fazendo com que, de um ponto de vista de confronto dessas diferentes cenas de recepção, Antoine Berman se projete como um autor de grande importância e centralidade no Brasil, mas, ao mesmo tempo, como um autor relativamente obscuro e marginal no mundo germânico, para citar aqui apenas um exemplo. ${ }^{4}$

E mesmo ao concentrarmos a atenção num único desses contextos de recepção, como o brasileiro, tampouco podemos falar de uma recepção que se dá de modo homogêneo. Se para muitos pesquisadores a imagem da obra de Berman ainda hoje se reduz ao que se apresenta em suas obras de maior circulação, como em A prova do estrangeiro (1984/2002) e em A tradução e a letra ou o albergue do longínquo (1985/2007), outros vêm se empenhando em repensar essa imagem a partir das várias (re)publicações mais recentes de sua obra, como em L'âge de la traduction (2008), Jacques Amyot, traducteur français (2012), Cartas para Fouad El-Etr (1968/2018), entre outras. É possível que o fato de Antoine Berman ter nos deixado precocemente (aos 49 anos de idade), sem ter tido a oportunidade de reorganizar, complementar, ampliar, reelaborar e/ou redirecionar seu pensamento (na maior parte dos casos, publicado esparsamente na forma de ensaios e artigos), contribua de modo significativo para esse caráter heterogêneo de sua recepção. De toda sua obra, apenas sua tese de doutorado (A prova do estrangeiro, 1984) foi publicada por ele, em vida, como livro. Os demais livros de sua autoria, embora organizados a partir de suas orientações gerais, foram todos publicados postumamente.

Na esteira das edições comemorativas organizadas por Martine Broda ${ }^{5}$ em 1999 e por Alexis Nouss em 2001,6 esta edição (coincidentemente a de

${ }^{4}$ L'épreuve de l'étranger (1984), uma de suas obras seminais e mais amplamente difundidas (publicada em tradução para o inglês em 1992 e em tradução brasileira em 2002), até hoje (maio de 2021) não foi contemplada com uma tradução para a língua alemã.

5 Broda, Martine (org.). La traduction-poésie. À Antoine Berman. Strasbourg: Presses Universitaires de Strasbourg, 1999.

${ }^{6}$ Nouss, Alexis (org.). Antoine Berman aujourd'hui. Antoine Berman for our time. Special issue, TTR 14, no. 2, 2001. 
número 30) da Tradução em Revista marca a efeméride dos 30 anos de morte de Antoine Berman com um gesto de retorno a sua obra e de (re)descoberta da complexidade e da potência de seu pensamento sobre a tradução, de que dão amplo e variado testemunho as contribuições aqui reunidas: um belo texto de abertura de Isabelle Berman, ${ }^{7}$ que descreve em síntese a trajetória intelectual do homem por trás da obra bermaniana, acompanhado de "Au début était le traducteur", texto inédito do autor, de caráter memorialístico, em que Berman destaca o modo como aspectos linguísticos, sociais, políticos e pedagógicos fundam sua relação com a tradução; 15 artigos e ensaios representativos de diversas perspectivas de discussão e reflexão, ou melhor, de diferentes formas de convivência com a obra bermaniana; 02 textos de Berman até então inéditos em português, "Mate e comunicação" (em tradução de Simone Petry) e "A essência platônica da tradução" (em tradução de Gilles Abes); e a tradução de "A ética do traduzir: Antoine Berman e a 'virada ética' na tradução" (em tradução de Patrícia Barbosa e Wellington Costa), de Barbara Godard, artigo comentado em vários dos textos desta edição.

Com “La crête de l'incendie: relecture des Lettres à Fouad El-Etr sur le Romantisme Allemand", Alexis Nouss, impactado pelo recente falecimento de Philippe Jaccottet, figura de grande inspiração e modelar para Antoine Berman, retorna às Cartas para Fouad El-Etr para pensar a relação de Berman com o Romantismo alemão como fundadora de sua obra por vir (sobre tradução). Já em seu "Pour une critique heureuse des traduction: mettre en dialogue les différences pour en éprouver la co-respondance", Marie Vrinat-Nikolov destaca a importância que Berman confere ao gesto de leitura do texto traduzido, em Pour une critique des traductions, para colocar em questão o modo persistente e anacrônico de se fazer críticas de tradução, fundado correntemente na lógica das perdas e dos ganhos. Defendendo uma crítica heureuse da tradução, capaz de aceitar a alteridade do texto traduzido, a autora desloca o foco de atenção da crítica de tradução para o modo como texto traduzido e original entram em diálogo, "fazem correspondência".

\footnotetext{
7 Agradecemos à Isabelle Berman pelo apoio generoso ao projeto desta edição e também pela cessão dos direitos dos textos de Antoine Berman.
} 
Em “Antoine Berman, tradutor de Augusto Roa Bastos", Adalberto Müller retoma a tradução que Berman faz de Yo El Supremo, de Roa Bastos, para mostrar que, se a reflexão crítica de Berman nos anos 70 antecede e alimenta a sua visão ética do traduzir, também sua prática de tradutor, nessa mesma época, antecipa uma ideia de convívio com o estrangeiro que já se manifesta como uma ética da diferença. Por sua vez, em "Pour Antoine Berman", defendendo a importância da obra bermaniana para se repensar as visões tradicionalmente dicotômicas da tradução, Kadhim Jihad Hassan mostra como, para Berman, a relação entre obra original e texto traduzido se encontra radicalmente inserida numa filosofia da diferença, sendo, portanto, tributária do pensamento de autores como Foucault, Deleuze e, principalmente, Derrida. Mobilizando assim um pensamento sobre a relação com o Outro, que reativa a relação com a língua e entre as línguas, o pensamento tradutório de Antoine Berman ganharia a força de um espaço de fecundação mútua e de hibridismo generalizado. Já em "Espaços translacionais, a tradução em devir: reflexões desde Antoine Berman", Álvaro Faleiros identifica a potência teórica que subjaz à reflexão de Berman sobre a noção de translação para elaborar seu conceito de "espaço translacional", que teria no espaço da (re)tradução um de seus princípios operadores e constitutivos.

Em “Gênese de uma disciplina: a Tradutologia”, Inês Oseki-Dépré parte de sua convivência com Antoine Berman e com aquilo que a aproxima e a afasta do pensamento do autor para propor uma discussão sobre a questão da "literalidade" na tradução. Já em "Berman et la traduction transparente", Jonas Tophoven se vale do conceito criado por seu pai, Elmar Tophoven, importante interlocutor de Berman, para reaproximar de novo os dois amigos e identificar possíveis pontos de convergência entre seus modos de pensar a tradução.

No seu texto "Método de análise e crítica de tradução de Antoine Berman: autorresenha do seu livro Por uma crítica da tradução: John Donne", Marie Heléne Torres apresenta uma síntese do esboço de um método de crítica da tradução, elaborado por Berman em Pour une critique des traductions. Também Gilles Abes se volta para uma questão importante da obra de Berman em seu artigo "Sobre o conceito de tradução platônica", procurando aprofundar a discussão desse conceito a partir de sua leitura de "A essência platônica da 
tradução", ensaio de Berman que o autor também traduziu para esta edição. Já em "Antoine Berman traduzido no Brasil", Clarissa Prado Marini faz um levantamento das obras de Berman traduzidas no Brasil e do contexto acadêmico em que essas traduções foram publicadas, chamando a atenção para aspectos terminológicos da tradução de alguns conceitos mais centrais.

A relação de Antoine Berman com a obra de outros autores é objeto de reflexão de dois outros textos. Em "Criação, tradução e crítica: diálogos entre Berman e Proust", Sheila Maria dos Santos aproxima (a despeito do tempo que os separa) os discursos de Antoine Berman e de Marcel Proust na condição de tradutores literários, identificando pontos de convergência, sobretudo no que diz respeito à crítica. Já em “Um momento favorável para estudar Stéphane Mallarmé pelas lentes retradutórias de Antoine Berman", ao partir do estudo da recepção crítica da obra de Mallarmé e de seu contexto de retradução no Brasil, Caroline Pessoa Micaelia se vale do pensamento bermaniano para destacar a importância da (re)tradução como ponto de partida para o estudo da poesia e de sua recepção crítica em geral.

Os 03 textos que encerram o conjunto de artigos e ensaios desta edição prestam homenagem a Antoine Berman a partir da rememoração da relação de cada uma de suas autoras com o pensamento do autor. Em "A tradução e a falha", Regina Helena de Oliveira Machado retoma suas anotações dos seminários de Antoine Berman no Colégio Internacional de Filosofia (especialmente as notas do seminário "A tradução e a Falha") para apresentar sua leitura particular do movimento do pensamento de Antoine Berman. Rosie Pinhas-Delpuech, em "Antoine Berman, traduire une violence premiére", oferece-nos um breve relato do modo como o pensamento de Berman sobre a tradução e sua natureza violenta foi se entrelaçando aos poucos com a compreensão de sua própria atividade como escritora e tradutora. Por fim, em "Le texte et la langue", partindo de uma reflexão sobre os atos de escrita e de leitura e relembrando seu contato com Berman na infância, Adrienne Orssaud nos fala do modo como o pensamento de Berman impacta sobre seu próprio ofício de tradutora e escritora.

Agradecemos muito sinceramente a todas as autoras e a todos os autores que atenderam à chamada para este número da Tradução em Revista, bem como 
àqueles e aquelas que não puderam fazê-lo em razão dos tempos difíceis que atravessamos em 2020 e 2021. Num gesto que se pretende mais como um convite à leitura desse conjunto de textos do que como uma síntese de suas valiosas contribuições, esperamos que esta edição especial, em homenagem a Antoine Berman, possa mobilizar uma nova forma de atenção à obra do autor, capaz de perceber os tensionamentos epistemológicos e a força ético-política de seu pensamento, bem como sua enorme contribuição para uma compreensão crítica dos mais diversos modos contemporâneos de (con)viver com a tradução.

Dedicamos esta edição à Isabelle, ao Nicolas, ao Alexandre e ao pequeno Sandro. 